\title{
ON THE DEVELOPMENT OF THE LYMPHATICS IN THE HEART OF THE EMBRYO PIG
}

JAMES R. CASH

\author{
Anatomical Laboratory of the Johns Hopkins University
}

This problem was approached by way of embryology primarily, because extensive lymphatic injections, in the adult heart, are impossible due to numerous valves in the lymphatic vessels. In embryos under $60 \mathrm{~mm}$. in length the valves have not formed and retrograde injection of the cardiac lymphatics is quite possible under the proper conditions. Also by observing the origin of the vessels in younger embryos and several further stages in their development it appears evident that observations made on the adult heart can be more rationally interpreted and the solution of the problem will be much nearer complete than if conclusions were drawn from the adult specimens alone.

The literature on the nature of the lymphatics of the heart is very scanty. The most pretentious and generally accepted work being that of $\mathrm{H}$. Bock of Munich.

Ranvier ('95) comes to the conclusion that there is considerable free space in the myocardium (that is, space between the muscle cells and blood vessels) and that this space is lymphatic in nature. This assumption is based on the fact that pericardial lymphatics can be injected by plunging the needle at random into the myocardium at any point. Thus the intercellular spaces and the lymphatics were supposed to be in direct connection. So the entire heart is considered to be a 'Iymphatic sponge,' as Ranvier expressed it.

Salvioli injected Berlin blue into the myocardium and made out what he thought were lymphatic vessels which ran in the connective tissue septa between the muscle bundles-but he could find no evidence of their connection with the intercellular spaces as advocated by Ranvier. 
Albrecht (87) in his work on the heart muscle, made an apparently very painstaking investigation of the subject. He injected the living heart, thus using its natural movement to distribute the injection mass. He came to the conclusion that the large lymphatic trunks lay in the spaces between the muscle cells. These large trunks he thought, were connected by straight lymphatic vessels of smaller size, which run at about right angles to the long diameter of the heart muscle cells and arrange themselves into a capillary network in the interior of the adjoining muscle bundle. The lymphatic vessels were observed to be straight and were differentiated from blood vessels which exhibit multiple and acute branching, and by the observation that blood vessels ran parallel to the long diameter of the muscle cells. Within the muscle bundle the lymphatic capillary network includes a muscle cell within each of its meshes. Albrecht made the further observation that the intercellular spaces which contain the large lymphatic trunks were not entirely filled by them, but that the lymphatic vessels lying in these spaces had their own walls, and that when injected, they could be seen lying over to one side of the space which was apparently empty. These spaces observed by Albrecht, were probably artefacts due to shrinkage of the tissue. Thus Albrecht concluded that an intercellular lymphatic capillary network existed with its own walls, and that it was in connection with the great interfasicular vessels which lay in the large spaces in the heart muscle (Henle spaces).

Bock ('05) criticized these statements of Albrecht severely. He points out very truly that in the previous work, the great discrepancy in reports lay in mistaking blood vessels for lymphatics. He attempted solution of the problem by making injections of both blood vessels and lymphatics in the same heart with different colored injection masses. The heart was placed in physiological salt solution and heated to body temperature, then kneaded thoroughly by hand to expel as much blood as possible. Cannulas were placed in the coronary arteries and carmine gelatine injected under pressure, thus filling the blood vessels with red. Berlin blue was then introduced quite forcibly into the myocardium: near the apex, by puncture with a hypodermic 
needle. The lymphatics of that area were thus supposedly injected, the blood vessels being already full of gelatine. The relations of the two systems of vessels should thus be demonstrated. The injected areas were cut out and sectioned. From their examination Bock reached the following conclusions:

1) Das Lymphgefässnetz stellt ein wàndhaltiges intermuskular verlaufendes Rohrensystem dar, genau wie die Blutkapillar Gefässsystem, nur noch vielgestaltiger und reichhaltiger.

2) Jede Muskelzelle hat ein Lymphkapillargefäss vielfach auch deren zwei und ein Blutkapillargefäss.

3) Lymph- und Blutkapillaren liegen meist dicht neben einander.

4) Lymphkapillaren verlaufen wie die Blutkapillaren parallel den Muskelzellen und ist die Muskelfibrille häufig von einer Anastomose zur langsverlaufenden Lymphkapillaren umspannt.

5) Die Lymphkapillaren sammeln sich in grossen Lymphbahnen.

6) Eine wirkliche Kommunikation mit spalten zwischen Muskeln konnte nirgends nachgewiesen werden.

7) Die Muskelzellen liegen in normalen Herzen ohne Spalten dicht nebeneinander und lassen nur Raum für die Lymph- und Blutkapillaren frei.

8) Spalten zwischen Muskelzellen sind pathologische und stets mit Bindgewebe ausgefüllt.

Thus Bock is of the opinion that the lymphatics of the heart' though following closely the pattern of the blood vessels, are much more numerous.

The most satisfactory method of approach to these problems in the study of lymphatics is through their embryology. The lymphatic vessels under study are thus followed through several stages of embryonic life.

Such was the method of procedure in this work, and it is offered as an addition to the series of embryological studies of lymphatics which have come from this laboratory. Embryo pigs of three stages were injected. At that time injections were made of both blood vessels and lymphatics of adult pigs' hearts.

\section{MATERIAL}

Pregnant uteri, recently removed from the body, were obtained from an abattoir near the laboratory. The hearts of the embryos were still beating regularly when the injections were made. 
The embryos were approximately of three stages: 1) 25 to 35 $\mathrm{mm}$. in length, showing the downgrowth of the right and left lymphatic ducts, both of which may be seen giving off branches to the trachea and lungs. Also the right duct may be seen sending off a branch to the heart forming a superficial plexus on its surface. 2) Embryos, 35 to $45 \mathrm{~mm}$. in length, showing the formation of the aortic and tracheal plexuses by the right and left ducts. The tracheal plexus may be seen giving off a rather large branch to the heart which is joined near its origin by the cardiac vessel, seen in the earlier stage coming from the right lymphatic duct. 3) Embryos, 45 to $65 \mathrm{~mm}$. in length, showing far greater richness of the lymphatic plexuses. The superficial cardiac plexus, seen in even the earliest injections, has increased greatly in area and its meshes are much smaller. The union of the two vessels from the right duct and the tracheal plexus is very well shown in embryos of this age. Embryos of greater length than $65 \mathrm{~mm}$. could not be injected, due to formation of numerous valves and nodes along the course of the lymphatic vessels which prevents the injection from flowing.

\section{METHODS}

The embryos were injected with either a saturated aqueous solution of Berlin blue or India ink. Number 28 hypodermic needles in an ordinary hypodermic syringe were used for injecting.

Injection was made from four sites. In the smallest embryos, the needle was introduced into the right jugular sac. By this method the right duct, passing down the right anterior cardinal vein and giving off a branch to the heart, was filled. In the other specimens ( 45 to $65 \mathrm{~mm}$.), the tracheal plexus, giving off the cardiac vessel, and the tributary from the right duct were injected by introducing the needle into the region just dorsal to the superior vena cava, which has formed at this age. (Cunningham,'16, Figs. 1-2.) Most of the injections of these older embryos were made by placing the needle directly into the thoracic duct just above the diaphragm. The entire left side of the body wall of the embryo was hurriedly dissected away and the needle quickly 
placed into the thoracic duct, which may be accurately located just between the azygos veins and the aorta. When injecting, the pressure must be sudden and rather powerful. Even when the needle is properly placed in the duct and the pressure properly applied, very few embryos show heart lymphatics. This is quite different from the case of most lymphatics of the body which fill readily, once the injection mass has free access to them. There have been several instances when the thoracic duct has ruptured under pressure without filling the cardiac lymphatics. The explanation of this lies in a mechanical consideration of the origin of the cardjac vessels. The ready filling of the intestinal and mesenteric lymphatics upon injection into the retreperitoneal sac is evidently due to the numerous and large branches of origin and the rich anastomosis on the vessels springing from them: if one pathway is blocked, the injection can go by another route. Then, too, in this location, the point of injection where the pressure is applied is near the vessels to be filled. The situation of the heart is entirely different. The thoracic duct reaches the openings of the tracheal plexus, a very dense and complex mass of vessels. From this plexus only one vessel goes to the heart, and this is the vessel that must be filled before the cardiac lymphatics can be injected from the thoracic duct. The tracheal plexus must be completely injected before the cardiac branch will fill. Injections of the heart are by no means assured even when the proper technique is carried out in making them. This is due, in great part, to the fact that the thoracic duct opens into the veins. Thus, back pressure is reduced, which accordingly greatly lessens the chances of complete retrograde injection of the tracheal plexus from so low a region of the thoracic duct. Such difficulty was eliminated, to a great extent, by placing a clamp around the great vessels at the base of the heart just before injection. So, too, in this way ink was prevented from entering the right chambers of the heart by way of the veins, as it inevitably did in specimens injected without the clamp and so prevented the clearing of the heart for study. Injections were also made into the retroperitoneal sac, and, though filling the lymphatics of the lungs, diaphragm, stomach and intestines very well, all failed to fill any of the car- 
diac vessels, the sac either rupturing under pressure or the injection entering the veins. Immediately after injection the specimens were hardened and bleached in Carnoy's fixing fluid. They were then transferred to 70 per cent alcohol and carried up the alcohols to absolute by 5 per cent changes and cleared by the Spalteholz method.

The gross specimens were prepared by approximately the same method used by Bock. Instead of kneading the hearts by hand to expel the blood, they were perfused through the coronary arteries with Locke's solution. It was found that freshly filled hearts could be revived to contraction in this way and that more blood was expelled by their own movement than could be squeezed out by hand. During the perfusion, the heart was suspended in physiological saline heated to $37^{\circ} \mathrm{C}$. After a few minutes' perfusion, Locke's solution was replaced by a saturated solution of Berlin blue which was forced through the coronaries at $40 \mathrm{~mm}$. $\mathrm{Hg}$. pressure. Punctures were then made at various points into the myocardium with a hypodermic syringe, injecting India ink into the muscle in the effort to fill the neighboring lymphatics. No matter how carefully this procedure was carried out, much of the ink flowed into blood vessels and the lymphatics injected at the same time could only be distinguished by their morphological characteristics; the color of the injected vessels counting for very little in their identification.

It can readily be seen that this is a very crude method of injecting cardiac lymphatics; however, it is the only one available since retrograde injection, through one of the large lymphatic vessels, lying just under the visceral pericardium, is impractical. This is due to the stoppage of the injection mass by the numerous valves in the cardiac vessels which begin to form at about $60 \mathrm{~mm}$. By injections into the myocardium at random, it is evident that it is only by chance that lymphatic vessels will be struck, and when once entered there is no reason to think that all the lymphatics of a given area will be filled. So, final conclusions should not be drawn from specimens so injected without substantiating the pictures seen in them by further investigation. In the attempt to obtain such evidence the following experiment was performed:- 
The left thoracic cavity of a cat was entered and several ribs just above the diaphragm resected. The parietal pericardium was split and several drops of ink injected into the myocardium of the beating heart. The ink that entered the blood vessels was quickly washed through them into the general circulation. Part of the ink could be seen to enter the pcricardial lymphatics immediately, but a good part of it remained as a circumscribed mass in the myocardium. The heart was allowed to beat from two to three hours in order that some of the ink might be absorbed by surrounding lymphatics. By this method no blood vessels were filled with which to confuse lymphatic vessels. The animal was then killed and strips of heart muscle in the regions of the injected drops of ink were fixed in 10 per cent formalin, cut in paraffin sections, stained in alum carmine for microscopic examination. One hundred $\mathrm{mg}$. of luminal sodium was used an an anesthetic and found to depress the cardio-respiratory centers very little. Since one lung was collapsed, artificial respiration was given throughout the entire experiment by Quinby's method of intra-tracheal insufflation ('09) at about $10 \mathrm{~mm}$. Hg. pressure. The animal's body temperature was maintained by placing the entire preparation in an asbestos lined box heated to $37^{\circ} \mathrm{C}$. It was found that several drops of ink could be placed into the myocardium at various points without embarassment of the heart's action.

This work was begun at the suggestion of Dr. R. S. Cunningham of this laboratory. I wish to thank him for the great assistance he has been to me.

\section{EMBRYOLOGY}

The lymphatics of the heart are found to arise from two sources: (1) the right lymphatic duct, which, in addition, gives rise to a lung vessel; (2) the tracheal plexus, which also sends vessels to the lungs.

The thoracic duct is formed by the union of vessels growing down from the left jugular sac and another plexus of vessels which bud off from the median mesonephritic vein, Baetjer ('08). The duct is shown to be a complete plexi $m$ structure 
in embryo pigs, $25 \mathrm{~mm}$. long (Sabin '13, Baetjer '08, Kampmeier '12).

The development of the tracheal plexus has been carefully studied and described by Cunningham in his work on lung lymphatics ('16) from which I quote the following:

About midway between the jugular anastomosis and the arch of the aorta, the thoracic duct leaves its position lateral to the trachea and bends downward to lie near the dorso-lateral border of the esophagus. In this position it comes down just behind the arch of the aorta. This transition is shown by Sabin (1913, figs. 12-13). Just as the duct begins to bend dorsally the earliest sprout to the lung is formed. At this point a single large vessel buds off from the thoracic duct and passes down over the arch of the aorta to the hilum of the lung. This vessel usually persists in the adult as one of the drainage trunks from the hilac nodes to the thoracic duct. From the region of the thoracic duct, where this vessel buds off to a point about the level of the aortic arch, a number of other vessels are formed very soon afterwards. These vessels arise very close together and grow across to the lateral wall of the trachea where they anastomose and form the primitive left tracheal plexus. They lie in the undifferentiated mesenchymal tissue that surrounds the tracheal lumen. These lymphatics have formed a plexus by the time the embryo has reached a length of $30 \mathrm{~mm}$. From this plexus vessels grow across the trachea to anastomose with other vessels from the similar plexus on the opposite side; other lymphatics grow up the trachea and form a coarse meshed plexus around it. This is the anlage of the adult supply of that structure. But the most important of the branches of this plexus, as far as the present work is concerned, are those from the lower part. These pass down the trachea, and, being joined by other vessels that leave the duct near the arch, pass up over the bifurcation into the lung.

The primary lymphatics to the heart are evidently those coming from the right lymphaties duct. Sabin (Origin and Development of the Lymphatic System, '13) states: "The right lymphatic duct curves ventralward and grows to the heart and lungs." Figure 13 of that work shows the right duct just anterior to the heart and located dorso-laterally to the trachea in a $25 \mathrm{~mm}$. pig embryo. Heuer ('09) (figs. 4 to 7) pictures a vessel from the thoracic duct which has every appearance of going to the heart. Though apparently leading to the heart, this vessel has never been seen to actually reach it; always entering the aortic plexus. It has been very cor tant in all the injections, but has never been seen in any wa onnect with the cardiac lymphatics. 
The right lymphatic duct arises from the right jugular sac and runs posteriorly, following the right anterior cardinal vein dorsally. At the level of the right duct of Cuvier it divides into two branches, one going into the hilum of the lung and the other passing ventrally between the trachea and right duct of Cuvier behind the aortic arch and the pulmonary artery to reach the anterior aspect of the heart, just to the left of the conus ateriosus. Injections of $40 \mathrm{~mm}$. embryos show a large vessel branching from the tracheal plexus at the base of the heart and turning ventrally near where the vessel from the right duct bends down. These two immediately anastomose by a single vessel and are seen to run closely parallel to each other. The branch from the right duct is evidently primary, preceding the branch from the tracheal plexus, which soon afterwards appears and follows its course to assist in the formation of the cardiac plexus. In some of the specimens, these two cardiac branches appeared almost as a single vessel from their point of anastomosis. The vessel to the heart from the right duct, together with the branch to the lungs, forms the early broncho-mediastinal trunk, the main pathway of cardiac drainage in the adult. However, they do not remain as two single vessels, but become plexiform in nature, receiving the drainage of the bronchial, anterior and posterior mediastinal, and sternal glands. The two small cardiac vessels, in the embryo, pass anteriorly under the pulmonary artery, lying between it and the left auricle, to the auriculo-ventricular groove about $.5 \mathrm{~mm}$. from the root of the pulmonary artery. Here, on the anterior surface of the heart, they form a primary plexus which gives rise to two main branches which in turn branch to form the pericardial plexus. One main branch passes to the left around the base of the left ventricle, following the auriculoventricular groove, to the posterior interventricular septum, down which it sends a branch. The other branch of the primary plexus passes around the base of the right ventricle and gives off a large branch, almost equal to itself in size, down the anterior interventricular septum, then passing around to the dorsal view of the heart, anastomoses with the left branch. Thus it is evident that the lymphatic invasion of the heart takes place 
along the larger blood vessels, as is charasteristic of all lymphatic development. The main vessels passing around the ventricular bases and down the interventricular septa give off numerous anastomosing branches along their course, in this way forming the pericardial plexus. This plexus lies in the submesothelial connective tissue just under the visceral pericardium. I do not feel that any of the injections of this plexus have been complete; however, at $40 \mathrm{~mm}$., the vessels passing down the interventricular septa have been filled almost to the apex and the pericardial plexus extending over at least one-half the surface area has been injected. At $60 \mathrm{~mm}$. the meshes of this plexus are much finer and more of the heart is covered. Whether injection is made through the right duct or the tracheal plexus there are only two vessels by which the heart lymphatics may be filled, so that, mechanically, it is very difficult to obtain good injections. In the cleared specimens of the $60 \mathrm{~mm}$. stage, no lymphatic vessels could be seen extending down into the myocardium, but along the larger vessels of the pericardial plexus short lymphatic buds are visible, starting down into the heart muscle. At this stage none of the pericardial lymphatics can be filled by injecting into the myocardium, as is so readily done in the adult heart. This experiment has been tried on hearts from pigs varying in size from 60 to $150 \mathrm{~mm}$., and none of them show myocardial vessels to any great extent. Even in the $150 \mathrm{~mm}$. embryos any of the surface lymphatics are only occasionally filled by injecting into the myocardium. Therefore, it appears that the pericardial plexus is formed almost completely before invasion of the myocardium takes place. Such inference seems logical, for it is evidently easier for the lymphatic growth to take place in the loose connective tissue under the visceral pericardium than to invade the heart muscle itself.

THE ADULT HEART

Gross inspection of the adult heart reveals numerous lymphaties on its surface just under the visceral pericardium. They are slender vessels of uniform size and form frequent anastomoses. Their course may be nearly straight or zig-zag. There is a 
large lymphatic vessel running down each side of the heart over the ventricular septum, and this receives a good many tributaries. The other surface lymphatics eventually drain into the large vessels along the auriculo-ventricular groove. The meshes of the pericardial plexus are much larger, relatively, than those of the $60 \mathrm{~mm}$. embryo, at which time the plexus is approximately densest. As the heart increases in size the lymphatics are stretched out, so to speak, to cover it, the plexus thus becoming less dense.

If a needle is plunged at random into the myocardium, some of the surface lymphatics can generally be filled. If a section is made of the ventricular wall and injection made from the cut edge near the pericardium, numerous surface lymphatics are always filled. If injection is made at a lower level, say about half the thickness of the ventricle, surface lymphatics will generally be filled, but they are not so numerous as when injection is made nearer the surface. If injections are made at over two-thirds the distance from pericardium to endocardium, only occasionally will surface lymphatics be filled. Injections made just under the endocardium never fill pericardial lymphatics, and in no case was an endocardial plexus of lymphatics found. In several places the His bundle was entered, and I think that positive statements in regard to an endocardial lymphatic plexus are based upon injections of this system which have been mistaken for lymphatics.

These observations indicate that there is a myocardial plexus draining into the pericardial plexus; and it appears that the vessels of the myocardial plexus become smaller and less numerous as they extend into the heart muscle. The relative difficulty of injecting them at different levels in the myocardium certainly calls for such an explanation.

The method of preparation of the adult cleared specimens in which both lymphatics and blood vessels were injected, has already been discussed. By cutting free hand sections about 2 $\mathrm{mm}$. in thickness from the injected regions, small areas can easily be found where blood vessels and lymphatics were both injected. The lymphatics are seen to follow the larger blood vessels, but 
not as single accompanying vessels as described by Bock. In the areas where the injections seem most complete, each of the larger blood vessels was seen to be surrounded by a scanty lymphatic plexus. The vessels making up these plexuses are all about the same size, and have comparatively few branches in comparison to the blood vessels. These lymphatics surrounding the larger blood vessels are connected by smaller vessels which complete the myocardial plexus. In many instances, these smaller lymphatics follow blood vessels, and, in others, can be seen to follow the connective tissue between the layers of the heart muscle. In no case were the lymphatic vessels seen to form a true capillary plexus which followed the blood capillaries, as has been described. The lymphatics anastomose freely while the blood vessels, as is well-known, form few or no anastomoses. All the injected specimens give the impression that the patterns of the blood vessels and lymphatics differ very much; the lymphatics never forming a capillary bed, but a well-woven plexus of vessels, of which the smallest are larger than capillaries. The lymphatic vessels become fewer and smaller as they extend deeper into the myocardium, their number being exceedingly small near the endocardium. The largest lymphatics are only about onefourth as large as the blood vessels they accompany, and the smallest ones are about the size of venules so that it is evident the cardiac lymphatics are more constant in size than are the blood vessels.

These observations are supported by the injection of living cats' hearts. Pericardial lymphatics were immediately filled in all cases when puncture was made, and myocardial vessels draining into them were seen in the sections. None of these myocardial lymphatics were seen to be as small as capillaries and their number was scanty. Absorption of the ink does not take place readily. This indicates the scarcity of lymphatic vessels in the myocardium, since India ink is readily absorbed by the lymphatics in those places where the vessels are abundant. Such slow absorption by the heart lymphatics. would certainly not take place if their number did not justify it. In no case did any lymphatic vessels appear on the endocardium, which would have been most likely had they been present. 
Most of the observers (to whom I have already referred) have doubtless seen both pericardial and myocardial lymphatics, but have been altogether too sweeping in drawing conclusions. Most of these vessels they have described have evidently been blood vessels. Most of Bock's illustrations of lymphatics are perfect pictures of blood vessels, while none of them resemble lymphatics. By this method, it is impossible to get complete injections of the blood vessels of the heart, and it appears that he has only described blood vessels injected with different colors. This point can be easily proven by observing a piece of heart muscle in which only blood vessels have been injected. In the double injections of the heart, many times the blood capillaries of an area will not be filled. When lymphatics of the same area are injected by puncture, some of the injection mass flows over into the unfilled blood capillaries, thus making a very misleading picture, large lymphatics and blood capillaries apparently belonging to the same system of vessels. Similar specimens probably have been the basis for statements to the effect that the lymphatics of the heart form a capillary plexus accompanying that of the blood vessels, but exceeding the blood plexus in density.

\section{SUMMARY}

1. The lymphatics of the heart arise from two sources: a) the right lymphatic duct; b) the tracheal plexus. Both these paths remain as ways of drainage in the adult, the branch from the right duct being the anlage for the bronchomediastinal trunk.

2. There is first formed a pericardial plexus covering the entire heart. This plexus reaches its greatest density at about $60 \mathrm{~mm}$. and becomes less dense as the heart increases in size.

3. From the injections it appears that after the pericardial plexus is approximately complete, vessels arising from it invade the heart muscle, and, by forming numerous anastomoses, growing to great extent along the veins, form the myocardial plexus. This invasion of the myocardium takes place rather late, at 150 $\mathrm{mm}$., there being relatively few myocardial lymph vessels demonstrable. 
4. The myocardial plexus becomes less dense as deeper points of the myocardium are reached.

5. The larger blood vessels of the heart are accompanied by a which are connected with plexuses around other large blood vessels by numerous anastomosing smaller lymphatics. These smaller lymphatic plexus composed of the largest lymphatic vessels vessels compose most of the myocardial plexus.

6. Cardiac lymphatics, in like manner to all other lymphatics, develop along the blood vessels.

7. Claims for an endocardial lymphatic plexus are evidently founded on partial injections of the His bundle.

8. The pattern of the lymphatics does not correspond to that of the blood vessels nor are the lymphatic vessels so numerous as has been supposed.

It is intended that this description of cardiac lymphatics will be included in a more extensive discussion of lymphatics which will appear later and will include illustrations of all the specimens mentioned in this work.

\section{LITERATURE CITED}

Albrecht, E. 1887 'Greifswald, J. Abel.

BAET,JER, W. A. 1908 Am. Jour. Anat., vol. 8.

Bock, H. 1905 Anat. Anz.

Budge, A. 1880 Arch. u. Phys. Anat. Abth.

Clark, E. R. 1909 Anat. Rec., vol. 3.

Cunningham, R. S. 1916 Contributions to Embryology, vol. 4, No. 12, Carnegie Institution of Washington.

Hever, G. 1909 Am. Jour. Anat., vol. 9.

Huntinaton, G. S. and C. F. W. McClure- 1906-1908-1910 Anat. Rec., vol. 1, Anat. Rec. vol. 2, Am. Jour. Anat., vol. 10.

KaMPMeier, O. F. 1912 Am. Jour. Anat., vol. 12.

Quinsy 1909 Johns Hopkins Bulletin.

Ranvier, L, 1895 C. R. Ac. des sc., vol. 121, p. 1105.

SABIN, F. R. 1913 Johns Hopkins Hospital Reports, Monograph-New Series, vol. 5 . 